\title{
INFÂNCIA, BRINQUEDO E LINGUAGEM ENTRE RECORTES E MONTAGENS
}

César Donizetti Pereira Leite

Tomamos como ponto de partida algumas citações:

A idéia de uma infância como uma 'substância psíquica' se revela então um mito, como aquela de um sujeito prélinguistico, infância e linguagem parecem assim remeter uma a outra em um círculo no qual a infância é a origem da linguagem $e$ a linguagem a origem da infância. Mas talvez seja justamente neste círculo que devemos procurar o lugar da experiência enquanto infância do homem (AGAMBEN, 2005a, p. 59).

Como infância do homem, a experiência é a simples diferença entre o humano e o linguístico. Que o homem não seja sempre já falante, que ele tenha sido e seja ainda infante, isto é a experiência. [...] Pois o próprio fato de que exista uma tal infância, de que exista, portanto, a experiência enquanto limite transcendental da linguagem, exclui que possa a linguagem ela mesma apresentar-se como totalidade $e$ verdade. [...] Experiência é mystérion que todo homem institui pelo fato de ter uma infância. Este mistério não é um juramento de silêncio e de inefabilidade mística; é, ao contrário o voto que empenha o homem com a palavra $e$ a verdade. [...] A verdade não é, por isso, algo que possa ser

\footnotetext{
* Professor Adjunto do Departamento de Educação UNESP Rio Claro
}

LEITE, César Donizetti Pereira. Infância, Brinquedo e Linguagens: Entre Recortes e Montagens. Revista Sul-Americana de Filosofia e Educação. Número 20: maio-out/2013, p. 45-63. 
definido no interior da linguagem, mas nem mesmo fora dela [...]. (AGAMBEN, 2005a, pp. 62-63).

O que é a linguagem:

Arrisquemos uma definição corriqueira: a linguagem é uma espécie de arca de brinquedo que se abre no chão do quarto. Índios de perna quebrada, elefantes sem tromba, bonecos sem cabeça, os carros amontoados sem rodas, peças perdidas do que um dia foi um quebra-cabeça. Um corpo demasiado grande para aquele espaço, lugares excessivamente amplos para corpos diminutos. Algumas peças permanecem, outras se perderam: a cada uso, uma nova montagem possível (BRASIL, 2008, p. 135).

Rosquinhas, pena, pausa, queixa, futilidade

Palavras como essas, sem ligação ou conexão entre si, são o ponto de partida de um jogo que, durante a época Bierdermeier, tinha grande prestígio. A tarefa de cada jogador era colocá-la num texto conciso de tal modo que a sua ordem não fosse alterada. Quanto mais curto o texto, quanto menos elementos medianos contivesse, tanto mais notável seria a solução. Esse jogo fomenta os mais belos achados sobretudo junto às crianças. Ou seja, para elas, palavras ainda são como cavernas, entre as quais conhecem curiosas linhas de comunicação. [...] Eis um exemplo que uma criança forja ligando as palavras citadas acima: "O tempo se lança através da natureza feito uma rosquinha. A pena colore a paisagem, e se forma numa pausa que é preenchida pela chuva. Não se ouve nenhuma queixa pois não há nenhuma futilidade" (BENJAMIN, 1995, p. 272). 
As citações acima se apresentam como ponto de partida de uma reflexão que desenvolveremos a partir de alguns trabalhos que temos realizado no campo de conexões entre cinema e educação. Tomaremos como lugar de ancoragem (1) uma constatação e (2) uma necessidade que emergiram deste trabalho. (1) Constatamos que, no campo do trabalho com 'cinema e educação' um campo de forças agem no sentido de um processo de modulação de subjetividades, que produzem modos de ser e de estar no mundo, neste sentido partiremos de certa ideia que relaciona a ideia de biopolítica e capitalismos estético e (2) surge então uma necessidade de refletir sobre 'linhas de fuga', possibilidades que emergem nos processos de produção de subjetividades. Para esta reflexão tomaremos uma pluralidade de olhares e reflexões em torno de vários temas e destacaremos aqui três deles, infância, linguagem e experiência. Tomaremos como ponto de articulação destas reflexões algumas idéias de brinquedo apresentadas por alguns autores, entre eles destacamos Vigotski (1989) e Agamben (2005a).

No contexto da pesquisa supracitada e das articulações que elas nos convidam a tecer, temos encontrado por um lado, infinitas possibilidades de acontecimentos e de produção de sentidos quando as crianças, durante a pesquisa, estão em situação de 'captura' das imagens, são produções cheias de nuances, povoadas de sensações e ricas em detalhes, porém, por outro, observamos reproduções de modos e formas de produzir sentidos quando as crianças estão diante de situações de montagens e edição de filmes. Estas reproduções, têm nos levado a refletir sobre situações de montagens e de possibilidades no contexto da pesquisa, sendo assim, este texto tem por objetivo discutir os espaços de produção de sentido a partir dos processos de montagens realizado pelas crianças, nas produções imagéticas desenvolvida pelas mesmas. Para tal, lançaremos mão de, em um primeiro momento apresentar a pesquisa, seus contornos e seu percurso, para depois trazer alguns elementos que contribuam para a problematização de uma reflexão em torno das montagens e suas variantes e finalmente encontrar as possibilidades de criação. 


\section{Recortes e contornos da pesquisa:}

Depois de ter alguma experiência em trabalhos de formação de professores e de nestes programas de formação ter escutado dos mesmos que já se encontravam cansados de oficinas, dos sempre mesmos e diferentes cursos, dizerem sempre diferentes e mesmas coisas, sobre as sempre inovadoras e velhas propostas, procuramos pensar um trabalho que partisse da visão da infância como possibilidade de abertura, como possibilidade do novo, como inacabamento, neste contexto, desenvolvemos um projeto junto à Professores do Ensino Fundamental da Rede Municipal de uma cidade no interior do Estado de São Paulo, que teve como eixo central pensar as articulações entre conceitos de infância e processos de formação docente, tomamos o cinema e mais especificamente alguns filmes como foco organizador das discussões, neste trabalho, tivemos a oportunidade de assistir 5 filmes junto com um grupo de cerca de 20 educadores (sendo 7 professores do ensino fundamental, 7 coordenadores e ou diretores de escola e 6 supervisores de ensino do Município), todos os referidos filmes foram pré-definidos por nós e após a sessão de vídeo discutíamos nossas impressões, sensações, idéias que as imagens nos provocam e procurávamos estabelecer relações com práticas educativas e os modos de ser e se fazer professor.

Havia nesta perspectiva de trabalho uma idéia em que no cinema e com as imagens neles presentes, nos permitiriam trabalhar com o que chamamos do sensível, daquilo que nos afeta, nos acontece, que nos passa, acreditávamos na possibilidade de sensibilização do outro, acreditávamos a priori que a imagem, e em linhas gerais a arte, por si próprias, produziriam, provocariam outras ordens de coisas, outros modos de olhar, acreditávamos que estas atividades produziriam inúmeras reflexões e percepções e que nos levariam a procurar/encontrar modos de re-invenção dos fazeres docente.

Se por um lado esta idéia sobre o cinema pode parecer um tanto 'romântica' e idealizada, para nós o que urdia era uma idéia de pensar a tensão existente no cinema entre gesto $e$ imagem, o lugar que nos permite dizer ou pensar no gesto como espetáculo e ainda o cinema como uma arte que escapa ao cálculo, 
pois nele se efetiva a relação de três entes, quem filma, quem é filmado e o espectador. Foi nesta perspectiva que o projeto foi constituído e desenvolvido.

Verificamos que de fato, um dos pressupostos deste trabalho foi se apresentando e se definindo como prováveis, ou seja, o cinema afetava, criava espaços marcantes de sensibilização, por outro lado, o que vemos acontecer foi um amontoado de clichês sendo apresentados, manifestados durante nossa conversa com os professores. Neste momento surgiu para nós uma forte constatação, de que a imagem trazia uma eficiente tecnologia cria mundos e modos de ser e estar neste mundo, se configurando assim, como um modo de 'capitalismo estético' agindo no campo da biopolítica.

Trabalharemos neste texto esta ideia de modo geral, procurando estabelecer relações entre o trabalho que desenvolvemos e o que dela e nele se colocam, sendo assim, 'biopolítica' se apresenta como uma noção de um poder produtivo $e$ presente, que aparentemente se apresenta a nós em meio a uma perspectiva de liberdade e de suposta autonomia, se estabelecendo por meio de uma série de estratégias que investem a vida humana, em suas dimensões biológica, subjetiva $e$ social, uma irrupção da naturalidade da espécie no interior da artificialidade política de uma relação de poder. Ou ainda o ingresso da vida nua no domínio da vida qualificada, da vida em comunidade, da vida política. Percebemos uma intensificação das estratégias biopolíticas, em razão de alguns fatores, vamos a eles: (1) uma convergência entre biopolítica e capitalismo avançado. Pois é por intermédio do

marketing, que o capitalismo acaba se interessando pela vida, não apenas como lugar da produção e do consumo, mas, principalmente, como uma inesgotável reserva de invenção. .... É um capitalismo que produz e reproduz não apenas mercadorias, mas modos de vida. (Brasil, 2008 ${ }^{1}$ ).

O que o capitalismo vende são serviços e o que ele compra são modos de ser. $\mathrm{O}$ que ele cria são mundos possíveis onde se pode experimentar estes modos do ser. Isto leva a pensar o capitalismo avançado também como capitalismo estético.

\footnotetext{
${ }^{1}$ As referencias que seguem abaixo, feitas ao texto de Brasil, não são literais, mas paráfrases do texto MODULAÇÃO/MONTAGEM: Ensaio sobre biopolítica experiência estética. Nossa opção foi parafrasear o texto com o propósito de adequá-lo a nossa discussão.
} 
Uma segunda estratégia no campo da biopolítica acena para a idéia de uma sociedade do risco e da insegurança.

No âmbito do Estado liberal, a insegurança é menos o que deve ser enfrentado, combatido, do que o que deve ser regulado. ////

A terceira estratégia no campo da biopolítica se refere

ao avanço cada vez mais acelerado da tecnociência, em aliança com as tecnologias da imagem e da informação. Essas tecnologias são menos ópticas do que algorítmicas $e$ elas permitem o mapeamento e a modulação do espaço, do tempo, do corpo e das subjetividades, intervindo não apenas em suas visibilidades no presente, mas, principalmente, naquilo que, no futuro, seria invisível.(Brasil, 2008)

E é aqui que encontro uma forte relação com meu trabalho. A biopolítica dentro daquilo que identificamos na relação dos professores com a imagem, com o cinema busca intervir justamente nessa dinâmica. Ela regula a errância da vida para tornar seu futuro adequado, suficiente, ou ainda o conjunto de técnicas, procedimentos e estratégias, através dos quais se modula a modulação da vida. (Brasil, 2008).

As modulações ou os clichês presentes nos ditos e nos modos de sentir, junto aos professores, criaram em nós a necessidade de encontrar outras formas para olhar para as afetações, e assumimos a perspectiva não de analisar, categorizar, interpretar as falas dos professores, usamos a estratégia de devolução a estes dos trechos de conversas, fragmentos de falas que produzidos em nossos encontros sobre os filmes. Esta alternativa encontrada foi a forma que pensamos ser possível para escapar às modulações e de encontrar espaços de montagens, espaços possíveis de produção de novos sentidos, de criação e re-criação do já dado, com os fragmentos de falas que 'devolvemos' ao professores estes teriam que compor, produzir sentidos para frases e palavras soltas, deslocadas do tempo $e$ das condições imediatas de suas produções ${ }^{2}$.

\footnotetext{
${ }^{2}$ Como não foi permitida a filmagem dos encontros com os professores, o único material que tínhamos eram as transcrições feitas por nós, estas transcrições se apresentavam na forma de pequenas frases e fragmentos de textos. Ao final das sessões de vídeo de debate sobre os filmes
} 
Foi a partir destes campos que orientei meu olhar para outros espaços de produções imagéticas e encontrei a infância e seu correlato mais próximo a criança. $\mathrm{Na}$ infância e pela criança estes modos de ser e estas modulações de espaços, de tempo e de corpos sendo construídos e sendo cuidadas em todos os detalhes nas e pelas imagens poderiam encontrar seu lugar em outros modos de ser em outras montagens. Então, procurando ampliar minhas leituras relativas aos processos de produção de subjetividade e de modos de ser na vida e voltando à infância, seu conceito e as aberturas que nele se inscrevem. Pautei-me também na imagem, na sua captura, em montagens e re-criações de sentidos e é neste contexto que surge o projeto: Ação, câmera, luz: entre imagens e olhares, experiência de infância $e$ montagens ${ }^{3}$, sobre o qual apresentarei algumas imagens, olhares e reflexões que tenho produzido a partir deste trabalho.

Então, se no cinema o projeto de um filme é dar conta de uma idéia criada a princípio, no projeto que estamos desenvolvendo um dos objetivos é observar, como que, sem uma idéia inicial, as crianças criam, compõem, produzem sentidos, na construção de suas narrativas imagéticas.

No desenvolvimento deste projeto tivemos vários momentos entre eles destacamos dois, (1) o primeiro em que as crianças sacavam as imagens (filmes $e$ fotografias) e o (2) em que as crianças diante destas imagens compunham sentidos e construíam suas narrativas. No primeiro momento observamos a força das ações, a potência das produções das crianças no intuito de filmar e fotografar, e as imagens apresentadas pelas crianças criaram vários movimentos abrindo muitos campos de reflexões e sensibilizações, um número bastante significativo de imagens digitais (fotografias) e de horas de filmagens, a variedade de imagens capturadas, aliadas a falta de técnica das crianças nos levaram a pensar sobre o potencial das expementações destas crianças e a infinidade de temas que elas nos convidam a pensar. No segundo momento (o das montagens), o que a princípio parecia um problema, pois voltamos a nos defrontar com os processos de modulações, acabou

voltamos este relato ao professores na forma de frases soltas e fragmentos de textos que conseguimos anotar, foi, então, solicitado aos professores que realizassem a partir destes relatos alguma produção, na forma de texto, que lhes parecian significativa.

${ }^{3}$ CNPQ (2009), Pró-reitoria de Pesquisa - UNESP (2009) e FAPESP (2010). 
abrindo um campo de reflexões em que o que a princípio parecia ser um problema, passou a indicar um campo de possibilidades, na verdade o que poderia ser espaços de modulação e de reprodução de formas já dadas de montar e produzir filmes, acabou se revelando como espaço de criação, de invenção, de produção de diferença, tanto dos sentidos como dos e nos modos de fazer/tecer.

Neste universo de possibilidades encontramos uma que nos pareceu estabelecer um espaço de reflexão a partir da idéia de brinquedo e de bricolagem. Tomamos como ponto de partida três autores que colaboram com esta discussão, são eles: Walter Benjamin, Giorgio Agamben e Lev Vigotski.

\section{Criação e Montagens - olhares:}

Em dois textos-fragmentos Benjamin (1984) é precioso ao descrever algumas das características das crianças. Tanto em Rua de Mão Única, como em Criança Desordeira ele nos mostra uma criança que se atrai pelos destroços, pelas coisas miúdas, por retalhos, por restos, nos sugere que esta atração não diz respeito a um propósito de imitação do adulto, mas sim que ela - a criança - a partir disso constrói mundos, constrói seus mundos, mundos pequenos (ou ainda poderia dizer mundo 'menor') - mundo delas - mundos que se inserem em mundos maiores.

É um mundo que possui sua própria lógica, mundo esvaziado da lógica adulta que sempre se impõe sobre o mundo das crianças, mas um mundo que não 'se organiza', não 'se arruma' em referências dadas antes de uma lógica já dada, mas 'lógicas de outros tempos e outras razões', um mundo inseguro e irascível.

Neste movimento entre mundos e crianças apresentado por Benjamin descobrimos uma forte valorização dos espaços de 'montagens' das crianças. Um verdadeiro movimento de bricolagem, onde se verifica acontecer uma mescla de imitação, invenção, re-invenção. No texto de Benjamin sobre o Bierdermeier (1995) vemos as crianças brincando com as palavras, sempre em jogos de composição, jogos de formação e de deformação das coisas. É necessário dizer que para que as crianças montem, criem e re-criem possibilidades, sentidos, jogos, palavras, figuras, coleções, elas são sempre postas e expostas a situações de cortes, re-cortes, desmontes de outros sentidos, outras palavras, outras figuras, outros objetos, outras situações. 
Este movimento é de ir e vir, quebrar e colar, romper e compor, destruir e montar. Movimento que atenta àquilo que resta, àquilo que sobra, que a mais nada parece servir, como este resto presente nas palavras de Marina, de 9 anos, na epigrafe do trabalho O lugar da imaginação na prática pedagógica da educação infantil (Leite, 2004): para ela "imaginação é pegar um monte de retalhos e colocar uns alfinetes".

Agamben (2005a), refletindo sobre a experiência de Pinóchio no País dos Brinquedos $e$ as relações apresentadas entre jogo e rito, em um estreito vínculo com o tempo, diz que esta vinculação é de uma ordem de inversão, ou seja, na mesma medida que o "rito fixa e estrutura o calendário; o jogo, ao contrário, mesmo que não saibamos ainda como e por que, altera e destrói" (2005, p.84). Nesta perspectiva, ele vai indicando uma relação de sacralização através do rito, $e$ por conseguinte, a sacralização de um determinado modo de viver o tempo: sagrado, sacralizado. É como se pela história de um tempo vivêssemos esta sacralização e definíssemos a própria História, também ela sagrada, também fixa, também estruturada em um calendário.

O jogo, então, assume um papel fundamental: o de 'profanar' aquilo que com o tempo se sacraliza, toma forma, toma totalidade nos objetos. Ou ainda, "brincando o homem desprende-se de um tempo sagrado e o esquece em um tempo humano" (AGAMBEN, 2005a, p. 85).

Mas não é só isso, acompanhando Benjamin podemos verificar que as crianças se sentem profundamente atraídas por aquilo que 'não serve mais', ou ainda 'por aquilo que já é resto', 'por aquilo que perdeu seu caráter de utensílio, sua validade, sua sacralidade'; se são estes os objetos integrais e sacralizados que as crianças destroem - em suas formas e sentidos - para construir outros, reais ou ficcionais, - e se os (des)objetos servem para serem de outra forma, servem para as criações, as re-criações e as re-invenções, então podemos dizer que esse brincar também serve para recriar no tempo, recriar o tempo.

Aquilo que o brinquedo conserva do seu modelo sagrado ou econômico, aquilo que deste sobrevive após o desmembramento ou a miniaturização, nada mais é que a temporalidade humana 
que aí estava contida, a sua pura essência histórica. O brinquedo é uma materialização da historicidade contida nos objetos, que ele consegue extrair por meio de uma manipulação particular. [...] $\mathrm{O}$ brinquedo, desmembrando e distorcendo o passado ou miniaturizando o presente [...] presentifica e torna tangível a temporalidade humana em si, o puro resíduo diferencial entre o 'uma vez' e o 'agora não mais' (AGAMBEN, 2005a, p. 87).

Assim, a criança, ao destroçar o brinquedo, os sagrados do brinquedo, seus sentidos já completos e o 'tempo' adulto embutido nele, pode ser também uma forma de 'tecer no brinquedo' um tempo que seja compatível com o seu, imprimir no objeto o seu tempo, tempo de criança, tempo da criança, a sua 'lógica' e também por que não dizer a sua falta de lógica, a sua 'outra coisa' que não necessariamente seja lógica. E é com isso os adultos tanto implicam, pois, ao seu olhar elas 'quebram' o brinquedo, mas o que deve mesmo é 'quebrar' algo neles, adultos. Alguns, os que sustêm sua criança 'interna' suportariam melhor essa 'implicação' (implicância), essas quebras. Poderíamos arriscar a dizer que diferente do que muitas vezes vem sendo pensado e trabalhado por alguns autores da Filosofia, da Filosofia da Educação e da Educação de um modo geral, não é o conceito e a idéia de infância de que estejam em crise, talvez não seja de um fim da infância que falamos, mas sim, vislumbrasse aqui que a crise pode estar no conceito e na idéia de adulto e, sobretudo de educador.

Para Agamben o brinquedo apresenta relações com a idéia de bricolagem, e indica que esta idéia se torna fundamental no pensamento de Levi-Strauss, para ilustrar esta idéia, a de um pensamento mítico.

Tal como a bricolage, também o brinquedo serve de 'fragmentos' (bricolage - briciola: fragmento diminuto de alimento, especialmente de pão, migalha; quantidade mínima de algo, bocado, partícula) e de peça pertencente a outros conjuntos estruturais [...] também assim o brinquedo transforma antigos significados em significantes e vice-versa (AGAMBEN, 2005a, p. 87).

Mas o que fica posto, tanto nas observações de Agamben como também nas de Benjamin, são as possibilidades de rupturas, quebras, cesuras com o já dado, o já dito, com o sacralizado, ou seja, é só a partir de algo dado, 
sacramentado, mas que também pode perder seu caráter de totalidade, de unicidade, que se criam as condições objetivas para espaços de outras montagens, de bricolagem. Portanto, a montagem não ocorre como algo isolado e fora de condições concretas e objetivas de vida, ocorre sobretudo nas ações e proposições daquele que monta. No caso da criança, parece estar exatamente aí o sentido e o fato do brinquedo.

Assim, e acompanhando Vigotski (1989) o brinquedo não é o objeto, não é propriamente o que se manipula, mas sim, a ação, a ação que profana, que cria rupturas, que transforma pau de vassoura em cavalo, caneta em avião, vassoura em guitarra, esta ação transformadora, de-formadora, abusada, que pode tirar o objeto de sua sacralização, de sua função (adulta - pedagógica) já dada.

A criação de uma situação imaginária não é algo fortuito na vida da criança; pelo contrário, é a primeira manifestação da vida da criança em relação as restrições situacionais. $\mathrm{O}$ primeiro paradoxo contido no brinquedo é que a criança opera com um significado alienado numa situação real. (Vigotski, 1989 p. 113).

Esta ação simbólica, acompanhada e modificada pela fala, também produz mudança significativa nesta palavra, que vai ao longo do tempo se tornando plural em sua significação, constituindo assim, através (não só, mas também) do brinquedo uma das características fundamentais dos processos de produção de subjetividade.

Se podemos caminhar nesta direção de pensar o brinquedo como esta ação transformadora, deformadora, criadora, re-criadora do real, podemos também pensar que a própria ação das crianças no projeto de pesquisa que com ela desenvolvemos acaba por ter uma característica próxima a característica do brinquedo, de uma ação que desmonta, que profana os olhares já apresentados, já apontados.

Desta forma, parece ser pela ação $e$ na ação que os processos de criação $e$ montagens, como algo longe de pretender fixar sentidos, materializar ordens únicas, ganham sua potência. Ela parte tanto da desmontagem daquilo que está na 
origem, ou seja, a profanação dos objetos na materialidade do tempo humano, quanto daquilo que está nos acontecimentos que ali se efetivam, ou seja, nos novos, diferentes e outros sentidos que ali se realizam e pontencializam.

\section{Montagens, Composições e Narrativas:}

Em Ninfas (2010), Giorgio Agamben relata a história de Henry Darger, um homem "tranquilo, pero ciertamente extravagante" (p. 21). Apresenta-nos um sujeito que possivelmente havia vivido em uma condição próxima do que poderíamos chamar de miserável, sobrevivendo como lavador de pratos em um hospital. Entre seus hábitos pouco comuns observa-se o fato de falar sozinho, quando muitas vezes imitava uma voz feminina, possivelmente de uma criança $e$ revirar latas de lixo.

Darger vivia em um apartamento em Chicago, de propriedade de Nathan Lerner, fotógrafo e designer novaiorquino. É Lerner quem, ao abrir as portas do apartamento onde por mais de 40 anos viveu Darger, se vê diante de um espaço inusitado:

Pero cuando Lerner, acompañado por un joven estudiante, entró en la estancia, se encontró con un descubrimiento inesperado. No le había sido fácil abrirse camino entre el montón de objetos de todo tipo (ovillos de bramante, botellitas de bismuto vacías, recortes de periódicos); pero, apilados en un rincón encima de un baúl viejo, había una quincena de volúmenes mecanografiados y encuadernados manualmente que contenían una de romance de casí trienta mil páginas, con un título elocuente: In the Realms of the Unreal (AGAMBEN, 2010, pp. 21 e 22).

Entre as mais diferentes situações observadas por Lerner ao percorrer o apartamento, ele relata que além da surpreendente história, seu inquilino era pintor, e que no período que ali viveu ilustrou sua história em "decenas y decenas de acuarelas y paneles de papel que en ocasiones, superaban a los tres metros de largos" (AGAMBEN, 2010, p. 22). Alternando os mais diferentes tipos de imagens e situações, o 'pintor' consegue, pela imagem, compor a sua história. Porém, apesar da obra extremamente rica em detalhes, é fato que Darger não sabia 
desenhar e mesmo pintar. Assim, o que realmente chama a atenção é a sua ação compositiva.

Lo que nos interesa de modo particular es el genial procedimiento compositivo de Darger. Como no sabía pintar mucho menos dibujar, recorta imágenes de chiquillas de albumes de dibujos animados o de periódicos y la calca con una especie de papel cebolla. Si la imágenes es demasiado pequeña, la fotografía y la amplía según sus necesidades. El artista consigue así disponer finalmente de un repertorio de modelos y gestos que puede combinar a su antojo (por medio de calco o collage) en sus grandes paneles. Así pues, Darger representa el caso extremo de una composición artística exclusivamente para Phathosformeln, que produce un efecto de modernidad extraordinaria (AGAMBEN, 2010, p.22 e 23).

Meu trabalho com 'montagens' no universo infantil da criança é inicial no sentido de que há muito a ser feito. Porém, o que posso observar é que as crianças começam a experimentar com as imagens que elas próprias produzem. Experimentações, olhares atentos, jogos constantes de produção de sentidos por relações dialógicas se fazem presentes o tempo todo. As negociações entre as crianças $e$ as aberturas nas escolhas das imagens parecem estar sendo um dos pontos centrais do que tenho observado.

Neste ponto, cabe salientar que nestas negociações se evidenciam jogos, práticas, exercícios de poderes nestes campos das produções de sentidos, estes vão sendo produzidos, constituídos, costurados. Ou seja, estamos notando que mais do que os sentidos produzidos, ou mesmo junto deles, que se produzem, há que se pensar sobre as práticas de poderes que as crianças vivenciam socialmente, e que nesse espaço de montagens também se manifestam e se praticam.

As crianças, diante das imagens produzidas por elas, não perdem a oportunidade de explorar. Há uma extensa e intensa exploração tanto das imagens já produzidas como também dos recursos tecnológicos apresentados, que elas tomam também como brinquedo. Elas brincam, colorem e descolorem. Mudam formas. Criam personagens. Inventam enredos. Produzem outros sentidos com sons e imagens, re-invetando os sentidos propostos. Assim as crianças usam e 
abusam do que têm, e produzem algo semelhante àquilo que Benjamin chamou de uma nova e incoerente relação com fatos, fotos e filmagens.

É interessante observar que com as mesmas imagens, com os mesmos recortes, com as mesmas cenas é possível construir, compor diferentes cenários, o que gostaria de destacar aqui é que se podemos pensar em uma abertura de sentidos, em uma possibilidade em que os sentidos não sejam sacralizados, a idéia de montagem parece apontar uma possibilidade muito potente nesta direção.

Ou seja, ao descontextualizar as imagens e as capturas dos sentidos préexistentes, as crianças criam outras lógicas, com outras perspectivas de passado, de origem. Nestes novos cenários, passado e origem não são eventos dados que ficaram para trás, que se supera em uma progressão cronológica do tempo, algo que está lá em uma relação já dada, a relação cronológica do tempo, linear, segura, contextualizada, mas passam a ser algo que pode ser inventado, re-criado, montado,

o que permanece e o que retorna sem cessar, como diferença. Dessa perspectiva, o passado se repete na forma de uma diferença, de uma recriação. Cada instante do tempo torna todo o passado novamente possível, leva o passado a um estado de potência (BRASIL, 2008, p.150).

Para Agamben (2005a), há a possibilidade de uma estreita relação entre infância, linguagem e experiência. Este autor afirma que linguagem e experiência não poderiam ser dissociadas, pois se assim fosse, a linguagem seria como um código vazio, sem vida. É através da experiência que entramos na linguagem e é na infância que experimentamos a vida na sua mais plena intensidade, distante das amarras da razão. Desta forma, nunca temos a totalidade da linguagem e de seus sentidos em nossas mãos assim como sempre nos pegamos pautados pelas perdas das experiências quando ficamos emersos na linguagem. Deste modo, linguagem e experiência se encontram na infância, nas suas possibilidades de aberturas e de inacabamentos.

Em linhas gerais, essa análise equivaleria a dizer que a cada vez que usamos a linguagem, temos que novamente reaprendê-la, reinventá-la. E se nós podemos dizer que a linguagem é o fio de Ariadne no labirinto, o fio de nossa história e de 
nossa constituição enquanto subjetividade, enquanto singularidade, a linguagem $e$ a recriação das crianças nos processos de montagens de cenas passadas e vividas pode ser pensada como o próprio processo de re-invenção da vida, e de si mesmo.

A idéia de 'ser' aqui, é a de ser pela e na linguagem, porém uma linguagem que, para além se suas formatações gramaticais, se infantiliza, em uma errância de termos, errância de idéias, errância de sentidos, errância de modos e errância de tempos, em sua composição: uma linguagem infantil. Uma linguagem estrangeira, uma linguagem da estrangeiridade da infância, deste não compreender direito as coisas, não compreender e não ser compreendido, uma linguagem que instaura um estado de alteridade em relação ao outro.

Essa idéia nos ajuda a crer que mesmo quando acreditamos que tudo já foi dito, estabelecido, definido, pensado, pela abertura da infância, da experiência e da linguagem, muito ainda permanece por ser dito, estabelecido, definido, pensado. Assim, a linguagem e suas linhas de abertura e montagem nos fazem sempre nos apresentar como se fôssemos crianças diante do mundo, e nos colocam sempre a necessidade de uma abertura para o que ainda não é, e que também nem foi.

No trabalho que estamos desenvolvendo acreditamos que a fuga a modulações presentes nas definições de nossos modos de ser e de estar no mundo se salvam nas criações, recriações, invenções e reinvenções, nisso que estamos chamando de montagens.

É por montagens que a criança, nos seus brinquedos com retalhos e cacos do cotidiano, reinventa e reconfigura espaços sensíveis de vida, em abertura $e$ possibilidades, e é assim que as crianças que dessacralizam objetos, profanando suas forças pré-definidas e arregimentando para eles novas forças, assim como as crianças 'colhem' as imagens capturadas livremente pelo seu corpo, pela câmera, pelo movimento do corpo, pelo uso da câmera, pelas explorações dos corposcâmeras e pelas tecnologias das câmerascorpos.

Nas montagens as crianças estão criando, inventando, desmontando $e$ montando, as crianças estão reconstruindo aquilo que lá era destroço, aquilo que já era caco, fragmento de cenas, imagens perdidas, imagens cortadas re-cortadas, 
pelo toque que liga e desliga, pelo olhar que escapa, pelo movimento rítmico que pula e para, pelas sensações, pelas vertigens, pelo tempo, pelas formações e pelas deformações dos olhares, das idéias, dos movimentos, dos desejos. Assim,

ao montar um objeto, um texto, um conjunto de imagens, manipulamos suas heterogeneidades, nos apropriamos de sua excessiva alteridade, para que desse processo surja um conhecimento, um pensamento. Como ressalta Didi-Huberman, a montagem implica sempre um processo de desmontagem - "a inflexão turbilhonária da destruição" - e de remontagem - "a inflexão estrutural de um autêntico desejo de conhecimento". O conhecimento que a montagem possibilita, contudo, não é nunca uma certeza. Ela é um procedimento que funde em um mesmo processo experiência sensivel e experiência cognitiva, aproxima o sensivel ao inteligível, tornando o logos indissociável do pathos. [...] Pela montagem, se conhece na mesma medida em que se sofre, se sente e se experiencia. $\mathrm{O}$ conhecimento que se produz aí apenas se descola, levemente, da experiência sensível, sem dela se abstrair totalmente. Algo que se aproxima daquilo que Rancière chamou uma poética do saber, uma poética em que o saber se constitui sempre de um não-saber. Ou do que De Certeau chamou uma estetização do saber, que se produziria, no cotidiano, por um "conhecimento que não se conhece" (BRASIL, 2008, p. 160).

Assim, vejo as crianças diante das imagens como esta possibilidade de ruptura com a homogeneidade do já dado, uma possibilidade que estaria também em profanar a ordem das coisas. Profanar, como entendido na linha de Agamben, 
é o movimento oposto ao de consagrar (sacrare): se a sacralização é uma retirada do mundo, que se torna alheio, distante da intervenção dos homens, a profanação é, em via inversa, sua restituição, por meio do uso. Em uma leitura equivalente e complementar, De Certeau defende a astúcia do uso, uma reutilização "desabusada" e desautorizada dos objetos, dos saberes, dos espaços, das tecnologias e linguagens. Uma espécie de bricolagem (Brasil, 2008, p.155).

A profanação presente na montagem aproximaria a linguagem da experiência e nos levaria de volta ao processo de criação presente na infância, aquela que monta, inventa, por suas imagens, verdadeiros trapos de linguagens, cacos de experiência, histórias, possíveis e inventadas, criadas e imaginadas e em meio ao uso dos recursos infantis da bricolagem, pelo qual se criem imagens próprias da educação, desssacralizadas, des-ritualizadas, usadas, inventando uma estética do ordinário, na qual um "pensamento que não se pensa", próprio da vida cotidiana, é atravessado por um "pensamento que ainda não pensa", pensamento estético (BRASIL, 2008, p.165). É assim que o trabalho com a imagem e com as crianças tem nos ajudado a pensar questões que se ocultam em outras esferas, ou, dito de outro modo, tem permitido uma experiência com imagens e infância.

\section{REFERÊNCIAS}

AGAMBEN, Giorgio. Infância e História: destruição da experiência e origem da história. Belo Horizonte, MG: Editora UFMG, 2005a.

AGAMBEN, Giorgio. Profanaciones. Buenos Aires, Argentina: Adriana Hidalgo Editora, 2005b.

AGAMBEN, Giorgio. O Que é o Contemporâneo? E outros dispositivos. Chapecó SC. Argos Editora, 2009.

AGAMBEN, Giorgio. Ninfas. Valencia, Espanha. Pre-Texto, 2010.

BARROS, Manoel de. Poesia Completa. São Paulo, SP, Leya Editora, 2010. 
BARROS, Manoel. Memórias Inventadas. São Paulo, SP, Editora Planeta, 2010b.

BENJAMIN, Walter. Reflexões: a criança, o brinquedo, a educação. São Paulo: Summus, 1984a.

BENJAMIN, Walter. Obras escolhidas I: magia e técnica, arte e política. São Paulo: Brasiliense, 1994.

BENJAMIN, Walter. Obras escolhidas II: rua de mão única. São Paulo: Brasiliense, 1995.

BENJAMIN, Walter. Obras escolhidas III: Charles Baudelaire, um lírico no auge do capitalismo. São Paulo, SP, Brasiliense, 1989.

BRASIL, André. ModulAÇÃo/MonTAGEM: Ensaio sobre biopolítica experiência estética. Tese de Doutorado. Programa de Pós Graduação em Comunicação Faculdade de Comunicação. Universidade Federal do Rio de Janeiro, 2008.

BOLLE, Willi. A idéia de formação na modernidade in Infância, Escola e Modernidade. São Paulo, SP: Cortez Editora, 1997.

COLLODI, Carlo. Pinóquio. Porto Alegre: L\&PM, 2005.

FOUCAULT, Michel. Microfísica do Poder. São Paulo SP: Editora Graal, 2009.

GALLO, Silvio. A Vila: Microfascismos, fundamentalismo e educação, in Fundamentalismo \& Educação. Belo Horizonte, MG: Autêntica, 2009.

GALLO, Silvio. Infância e Poder: algumas interrogações à escola, in Devir-criança da Filosofia. Belo Horizonte, MG: Autêntica, 2009.

KOHAN, Walter. Infância, estrangeiridade e ignorância. Belo Horizonte. MG: Autêntica, 2007.

LEITE, Adrian Regina Isler Pereira. O Lugar da imaginação na prática pedagógica da Educação Infantil. Tese de Doutorado, Educação, Universidade Metodista de Piracicaba, Piracicaba, SP. 2004.

LEITE, César D.P. Labirinto: infância, linguagem e escola. Taubaté, SP: Cabral Editora Universitária, 2007.

MASSCHELEIN, Jan. E-ducar la mirada. La necesidad de una pedagogía pobre in Educar La Mirada: Politicas y Padagogía de la Imagen. Buenos Aires Argentina: Ediciones Manantial, 2006.

RANCIÈRE, Jacques. Políticas da escrita. Rio de Janeiro, RJ: Editora 34, 1995.

RANCIÈRE, Jacques. O Mestre Ignorante. Belo Horizonte, MG: Autêntica, 2004. 
SCHÉRER, René. Infantis: Charles Fourier e a infância da crianças. Belo Horizonte, MG: Autêntica, 2009.

VEIGA NETO, Alfredo. Foucault e a Educação. Belo Horizonte, MG: Autêntica, 2003.

VIGOTSKI, Lev S. La imaginación y el arte en la infancia. (trad.) Cidade do México: Hispânicas, 1987. (Original de 1930)

VIGOTSKI, Lev S. Pensamento e linguagem. (trad.). São Paulo: Martins Fontes, 1989. 